\title{
Primary Interosseous Meningioma associated with Pregnancy -Case Report-
}

\author{
Tatsuya NiSHIOKA, Akinori KoNDO, Ikuhiro AOYAMA, \\ Katsumi SHIMOTAKE, Jun TAKAHASHI and Hirofumi KUSAKA*
}

\author{
Departments of Neurosurgery and *Neurology, \\ Kitano Medical Research Institute \\ and Hospital, Osaka
}

\begin{abstract}
The authors present the case of a 32-year-old female with a hard, bony mass on her left forehead, present for several years, which rapidly increased in size after she became pregnant. Neuroradiologically, the tumor appeared to have originated in the interosseous space, and it invaded the subgaleal and intracranial spaces as the pregnancy advanced. The tumor was explored and removed after delivery. Light and electron microscopic studies verified that it had the characteristics of a typical meningotheliomatous meningioma. Interosseous meningiomas are biologically and morphologically similar to intracranial meningiomas and must be followed carefully during pregnancy because of their potential for rapid growth at this time.
\end{abstract}

Key words: interosseous meningioma, pregnancy

\section{Introduction}

Primary interosseous meningioma is rare, and its pathogenesis is controversial. ${ }^{2,18,33,42)}$ We report a case of interosseous meningioma that progressively enlarged during pregnancy. The clinical and morphological features are briefly discussed.

\section{Case Report}

A 32-year-old female consulted a local hospital because of a firm mass on the left side of her forehead, which had been present for several years. A computed tomographic (CT) scan obtained on April 7, 1986, showed slight thickening of the left frontal bone with no apparent subgaleal or intracranial mass lesions (Fig. 1 left). She later became pregnant and, as the pregnancy advanced, the mass rapidly enlarged. She delivered a baby without perinatal complications on August 7, 1987, and afterward was referred to our clinic. There was no history of trauma or other significant events besides pregnancy prior to the development of this tumor.

Physical examination disclosed a bony swelling in the left forehead measuring about $7 \times 7 \times 2.5 \mathrm{~cm}$. The skin covering the mass was normal. Neurological examination showed no significant abnormalities. A plain skull $x$-ray showed left frontal hyperostosis with spicular formation. A brain scan with technetium-99m showed a large area of high uptake in the corresponding region. A CT scan demonstrated thickening of the left frontal bone and a homogeneously enhanced intracranial mass (Fig. 1 right). A left internal carotid angiogram revealed an avascular lesion subjacent to the hyperostotic area. The tumor was not supplied by any meningeal arteries, but was shown by left external carotid angiography to be fed by dilated frontal branches of the superficial temporal artery (Fig. 2). Magnetic resonance (MR) imaging revealed an interosseous neoplasm

Received February 3, 1989; Accepted April 25, 1989

Author's present address: T. Nishioka, M.D., Department of Neurosurgery, Kyoto University Medical School, Kyoto, Japan. 

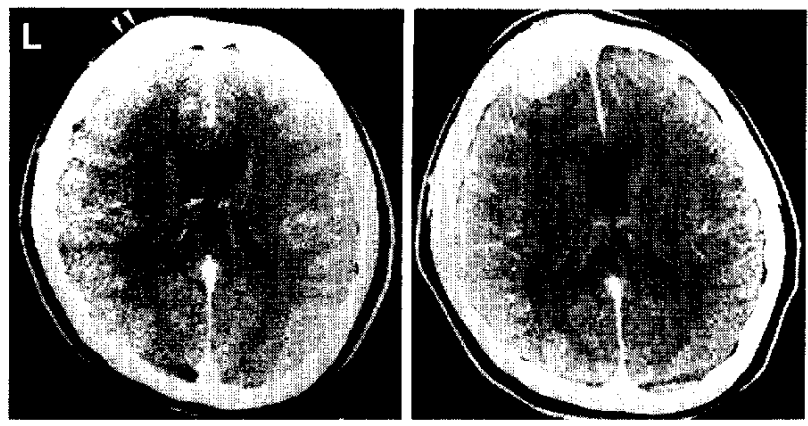

Fig. 1 Postcontrast CT scans. left: Before pregnancy. Note the local hyperostosis of the left frontal bone (arrowheads). right: On admission, a homogeneously enhanced intracranial tumor is clearly visible.

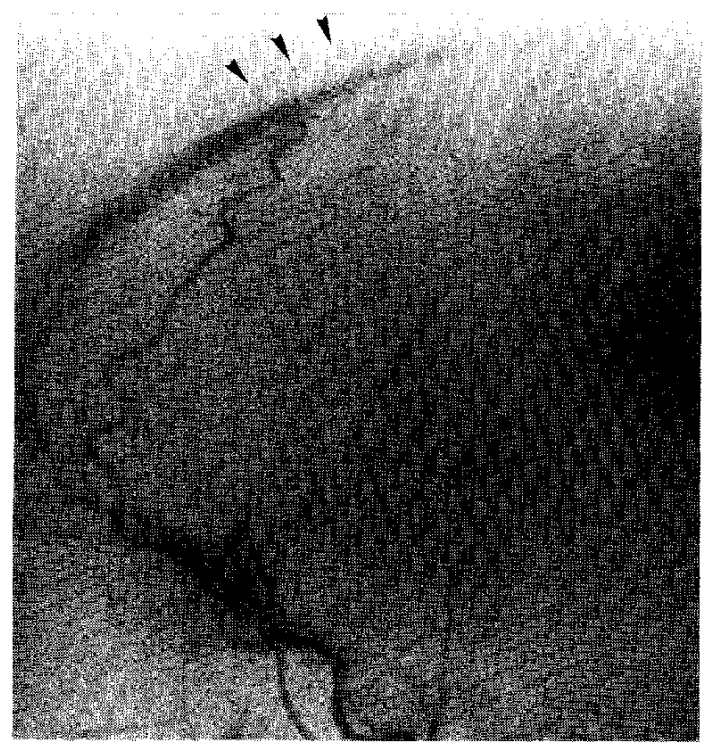

Fig. 2 Left external carotid angiogram, lateral view. A frontal branch is dilated in the vicinity of the left frontal tumor (arrowheads).

with subgaleal and subdural components (Fig. 3).

At surgery, a coronal skin incision was made and the subgaleal soft tissue mass, which firmly adhered to the subjacent bone, was completely removed. The hyperostotic portion of the skull and the surrounding bone were excised in one piece. The affected bone had no relationship with any skull sutures. The underlying dura was gritty and thickened, and appeared to be involved by the tumor. Extensive excision of the dura exposed the subdural portion of the tumor, which was whitish-gray, firm, and well circumscribed. The brain parenchymal tissue appeared intact. After en bloc removal of the tumor, the affected dura was replaced with lyophilized dura. Her postoperative course was uneventful.

Sections of the tumor tissue stained with HE showed the mass to be composed of elongated or polygonal cells throughout both the subgaleal and subdural portions (Fig. 4). These cells formed whorls in some places. No typical psammoma bodies were observed. Sections of the thickened bone showed tumor islands filling the intramedullary spaces. Each section of all the tumor components showed essentially the same microscopic features.

The specimens taken from an intracranial portion of the tumor were immediately fixed in $5 \%$ glutaraldehyde, embedded in Epon, routinely processed, and observed under the electron microscope. The tumor cells had very complicated outer surfaces, including interdigitation with adjacent cells (Fig. 5 left). They were studded with numerous desmosomes. The cytoplasm was relatively simple, containing short strips of rough endoplasmic reticulum, dispersed mitochondria, and Golgi apparatus. They also possessed oval nuclei with small clumps of heterochromatin. Some nuclei displayed nucleoli or cytoplasmic pseudoinclusions. At higher magnification the cell surfaces also exhibited extensive interdigitation, with desmosomes and bundles of intermediate filaments (Fig. 5 right).

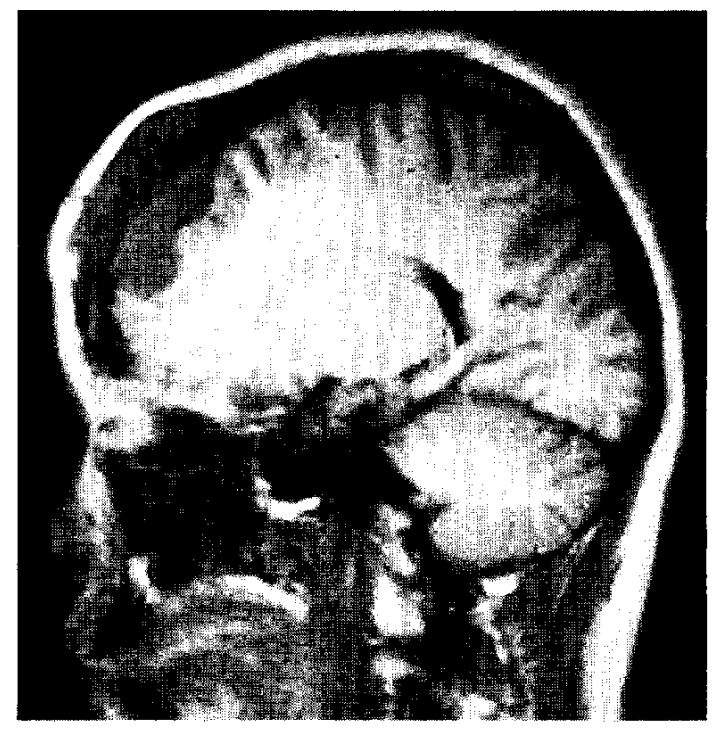

Fig. 3 MR image, sagittal section, demonstrating the interosseous lesion, which involves both the subgaleal and subdural spaces (TR, $2400 \mathrm{msec}$; TI, 600 msec). 


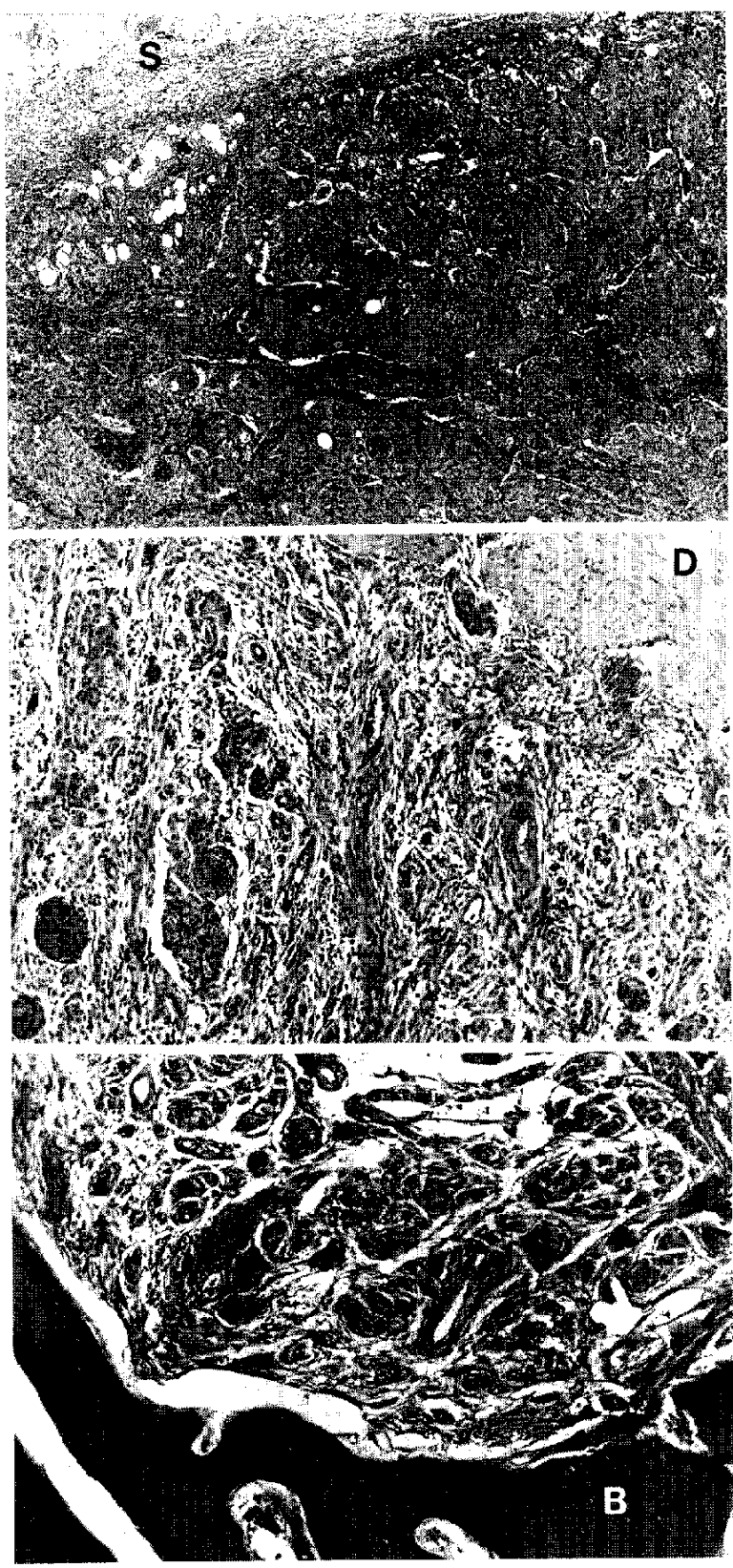

Fig. 4 Light photomicrographs of HE-stained surgical specimens from the subgaleal (upper, $\times 25$ ), subdural (middle, $\times 50$ ), and interosseous (lower, $\times 50$ ) portions of the tumor. Meningioma cells are present throughout these sections. $\mathrm{S}$ : subgaleal connective tissue, D: dura mater, B: bony matrix.

\section{Discussion}

Ectopic meningioma is a well known, although infrequent, entity and reportedly occurs at various

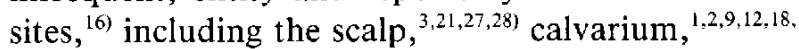

24,25,29-33,37,39-42,46) orbit, $^{13,16)}$ paranasal sinuses, ${ }^{17,23,34,38)}$ parotid gland, ${ }^{10,45)}$ lung, ${ }^{5,14)}$ skin, ${ }^{3)}$ and other locations. $22,43,44)$

Excluding secondary interosseous meningiomas, $\left.{ }^{6}\right)$ which are intracranial meningiomas that have extended into the calvarium, the pathogenesis of socalled primary "interosseous" meningiomas remains obscure. In general, ectopic meningiomas of the calvarium are believed to derive from arachnoid cells that have been incorporated into the skull during development, since such meningiomas usually occur along the skull sutures..$^{2,32,33,37)}$ Trauma is also thought to be responsible for some primary interosseous meningiomas, the assumption being that a part of the dura containing arachnoid cells becomes trapped in the fracture line and later develops into a meningioma. ${ }^{27,30,40,42\}}$ In our patient, the tumor had no relationship with the cranial sutures and there was no history of trauma. Nonetheless, this tumor was suspected to have originated in the interosseous space, on the basis of the initial CT findings and the fact that it was supplied by the superficial temporal artery alone. It is, therefore, quite likely that the tumor arose from ectopic arachnoid cell rests present within the bone, in a manner similar to that described in some cases of cutaneous meningioma. ${ }^{3,211}$

Meningiomas have often been noted to become symptomatic during or after pregnancy., ${ }^{7,8,19,35)}$ The reason for this is unknown, but it is noteworthy that, in our case, invasion into the intracranial cavity occurred during pregnancy, as shown by serial CT scans. This is the first reported case of a primary interosseous meningioma rapidly increasing in size during pregnancy. The tumor was not tested for estrogen or progesterone receptors, but its rapid enlargement, as well as that in some reported cases of intracranial meningiomas, ${ }^{7,8,19,35)}$ can probably be ascribed to hormonal changes during pregnancy.

The ultrastructure of several "ectopic" meningiomas has been described,,$^{5,14,22,25,28,44)}$ as has that of one intraosseous malignant meningioma. ${ }^{203}$ According to these reports, ectopic and intracranial meningiomas are indistinguishable. The characteristic electron microscopic features of intracranial meningiomas include marked interdigitation of cell membranes, with desmosomes and intracytoplasmic microfilaments; ${ }^{4,11,15,26,36)}$ these are identical with the features of our case. We diagnosed our patient's tumor as a typical meningotheliomatous meningioma electron microscopically, and the light microscopic features also conformed to this diagnosis.

In conclusion, interosseous meningiomas are biologically and microscopically identical to their 

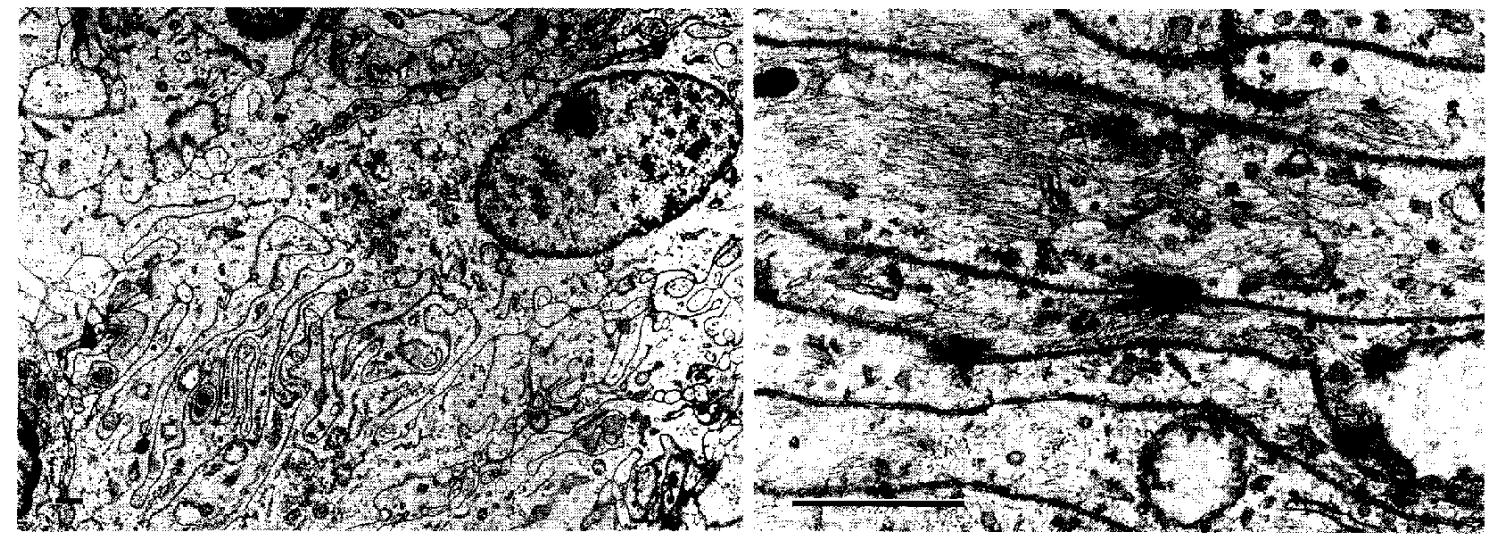

Fig. 5 Electron photomicrographs of the intracranial surgical specimen. left: Meningothelial cells showing complex interdigitation with neighboring cells. Bar $=1 \mu \mathrm{m}$. right: Higher magnification of a cell surface, disclosing intermediate filaments as well as desmosomes. Bar $=1 \mu \mathrm{m}$.

meningeal counterparts. Pregnant women with such tumors should be closely observed.

\section{References}

1) Alpers BJ, Harrow R: Cranial hyperostosis. Arch Neurol Psychiat 28: 334-356, 1932

2) Azar-Kia B, Sarwar M, Marc JA, Schechter MM: Intraosseous meningioma. Neuroradiology 6: 246253, 1974

3) Bain GO, Shnitka TK: Cutaneous meningioma (psammoma). Report of a case. AMA Archives of Dermatology 74: 590-594, 1956

4) Cervós-Navarro J, Vazquez JJ: An electron microscopic study of meningiomas. Acta Neuropath (Berlin) 13: 301-323, 1969

5) Chumas JC, Lorelle CA: Pulmonary meningioma. A light- and electron-microscopic study. Am $J$ Surg Pathol 6: 795-801, 1982

6) Cushing H: The cranial hyperostosis produced by meningeal endotheliomas. Arch Neurol Psychiat 8: 139-154, 1922

7) Degrood RM, Beemen WH, Fenner DE, Compton AA: A large meningioma presenting as a neurologic emergency in late pregnancy. Obstet Gynecol 69: 439-440, 1987

8) Goldberg M, Rappaport ZH: Neurosurgical, obstetric and endocrine aspects of meningioma during pregnancy. Isr J Med Sci 23: 825-828, 1987

9) Hamada H, Kadota K, Uetsuhara K, Asakura T: Extracalvarial meningioma. A case report. No Shinkei Geka 5: 633-639, 1977 (in Japanese)

10) Hoye SJ, Hoar CS Jr, Murray JE: Extracranial meningioma presenting as a tumor of the neck. Amer J Surg 100: 486-489, 1960

11) Humean $C$, Vic $P$, Sentein $P$, Vlahovitch $B$ : The fine structure of meningiomas: An attempted classifica- tion. Virchows Arch [Pathol Anat] 382: 201-216, 1979

12) Kaneko F, Takase $K$, Nishiyama $K$, Kusaka $K$, Morizumi H, Matsumoto K: Report of a case of intraosseous meningioma. No Shinkei Geka 16: 197202, 1988 (in Japanese)

13) Karp LA, Zimmerman LE, Borit A, Spencer W: Primary intraorbital meningiomas. Arch Ophthalmol 91: 24-28, 1974

14) Kemnitz P, Spormann H, Heinrich P: Meningioma of lung: First report with light and electron microscopic findings. Ultrastruct Pathol 3: 359-365, 1982

15) Kepes J: Electron microscopic studies of meningiomas. Amer J Path 39: 499-510, 1961

16) Kepes JJ: Meningiomas: Biology, pathology, and differential diagnosis, in: Masson Monographs in Diagnostic Pathology. New York, Masson, 1982, pp 40-47

17) Kjeldsberg $C R$, Minckler $J$ : Meningioma presenting as nasal polyps. Cancer 29: 153-156, 1972

18) Konishi $Y$, Kadowaki C, Shiogai T, Ogashiwa M, Takeuchi K, Fukuzumi N: Osteoid osteoma associated with intraosseous meningioma. A case report. No Shinkei Geka 12: 1403-1408, 1984 (in Japanese)

19) Kuratsu J, Matsukado Y: Sex hormone receptor in meningioma. Neurol Med Chir (Tokyo) 22: 10091013, 1982 (in Japanese)

20) Lee WH, Tu YC, Liu MY: Primary intraosseous malignant meningioma of the skull: Case report. Neurosurgery 23: 505-508, 1988

21) Lopez DA, Silvers DN, Helwig EB: Cutaneous meningioma. A clinicopathological study. Cancer 34: $728-744,1974$

22) Mackay B, Osborne BM, Guillamondegui OM: Case 13. Ultrastruct Pathol 5: 353-357, 1983

23) Majoros M: Meningioma of the paranasal sinuses. Laryngoscope 80: 640-645, 1970

24) McWhorter JM, Ghatak NR, Kelly DL Jr: Extra- 
cranial meningioma presenting as a lytic skull lesion. Surg Neurol 5: 223-224, 1976

25) Miyaguchi $M$, Uda $H$, Miyamoto K, Sakagami M, Sakai S, Ishida M, Aruga H, Ohira S, Yoshihara W: Two cases of extracranial meningioma. $J$ Clin Electron Microscopy 17: 5-6, 1984

26) Napolitano L, Kyle R, Fisher ER: Ultrastructure of meningiomas and the derivation and nature of their cellular components. Cancer 17: 233-241, 1964

27) Nishimura $K$, Saito $T$, Kojima M: Cutaneous meningioma: Report of a case. Gan No Rinsho 16: 10021008, 1970 (in Japanese)

28) Nochiomovitz LE, Jannotta F, Orenstein JM: Meningioma of the scalp. Light and electron microscopic observations. Arch Pathol Lab Med 109: 9295,1985

29) Ohaegbulam SC: Ectopic epidural calvarial meningioma. Surg Neurol 12: 33-35, 1979

30) Palma L, Mercuri S, Ferrante L: Epidural calvarial meningioma. Surg Neurol 8: 315-318, 1977

31) Pearl GS, Takei Y, Parent A, Boehm WM Jr: Primary interosseous meningioma presenting as a solitary osteolytic skull lesion. Case report. Neurosurgery 4: 269-270, 1979

32) Pendergrass EP, Hope JW: An extracranial meningioma with no apparent intracranial source. Report of a case. Amer J Roentgen 70: 967-970, 1953

33) Rahoria SK, Gulati DR: Intraosseous meningioma. A case report. Neurol India 26: 79-80, 1978

34) Rao SB, Dinakar I, Reddy CR: Meningioma of the frontal sinuses. Report of two cases. J Neurosurg 36: 363-365, 1972

35) Roelvink NCA, Kamphorst W, van Alphen HA, Rao BR: Pregnancy-related primary brain and spinal tumors. Arch Neurol 44: 209-215, 1987

36) Scheithaner BW, Bruner JM: Central nervous system tumors. Clinics in Laboratory Medicine 7: 157-179, 1987
37) Siegel GJ, Anderson PJ: Extracalvarial meningioma. Case report. $J$ Neurosurg 25: 83-86, 1966

38) So NC, Ngan H, Ong GB: Ectopic meningiomas. Report of two cases and review of literature. Surg Neurol 9: 231-237, 1978

39) Taveras JM, Wood EH: Diagnostic Neuroradiology. Baltimore, Williams \& Wilkins, 1964, p 158

40) Turner OA, Laird AT: Meningioma with traumatic etiology. Report of a case. J Neurosurg 24: 96-98, 1966

41) Waga $S$, Nishikawa $M$, Ohtsubo $K$, Kamijyo $Y$, Handa H: Extracalvarial meningiomas (2 cases). Neurology (Minneap) 20: 369-372, 1970

42) Wagman AD, Wiess EK, Riggs HE: Hyperplasia of the skull associated with intra-osseous meningioma in the absence of gross tumor. Report of three cases. $J$ Neuropathol Exp Neurol 19: 111-115, 1960

43) Wilson AJ, Ratliff JL, Lagios MD, Aguilar MJ: Mediastinal meningioma. Case report. Am J Surg Pathol 3: 557-562, 1979

44) Wolff M, Rankow RM: Meningioma of the parotid gland. An insight into the pathogenesis of extracranial meningiomas. Hum Pathol 2: 453-459, 1971

45) Young PH: Solitary subcutaneous meningioma appearing as an osteolytic skull defect. South Med $J 76$ : 1039-1040, 1983

46) Zaritzky D, Cowan RJ: Interosseous meningioma. An unusual radionuclide presentation. $J$ Nucl Med 18: 943-944, 1977

Address reprint requests to: T. Nishioka, M.D., Department of Neurosurgery, Kyoto University Medical School, 54 Shogoin, Kawahara-cho, Sakyo-ku, Kyoto 606, Japan. 